\title{
Trastuzumab induced radiation recall dermatitis: an interesting case
}

\author{
Anupama C. ${ }^{1}$, Anuradha H. V.1, Vinayak V. Maka ${ }^{2 *}$
}

${ }^{1}$ Department of Pharmacology, MS Ramaiah Medical College, Bangalore, Karnataka, India ${ }^{2}$ Department of Medical oncology, MS Ramaiah Medical College and Hospitals, Bangalore, Karnataka, India

Received: 04 October 2018 Accepted: 26 October 2018

\section{*Correspondence to:}

Dr. Vinayak V. Maka, Email: vinayakvmaka@ gmail.com

Copyright: (C) the author(s), publisher and licensee Medip Academy. This is an openaccess article distributed under the terms of the Creative Commons Attribution NonCommercial License, which permits unrestricted noncommercial use, distribution, and reproduction in any medium, provided the original work is properly cited.

\begin{abstract}
Radiation recall dermatitis (RRD) is the appearance of skin reactions in previously irradiated skin which is triggered by the administration of certain drugs. Surgery, chemotherapy, and radiotherapy are the mainstay of treatment in breast cancer. RRD induced by trastuzumab has been rarely reported in India. This is a case report of a 56-year-old woman presented to the medical oncology outpatient department of our hospital with breast lump, and she was diagnosed to have human epidermal growth factor receptor 2 (HER-2/neu) positive invasive ductal carcinoma of left breast of stage $\mathrm{T}_{2} \mathrm{~N} 3 \mathrm{cM}_{0}$. She was treated with neoadjuvant chemotherapy, and she underwent modified radical mastectomy with axillary lymph node dissection. The treating oncologist was planned to start on adjuvant chemotherapy with injection trastuzumab for every four weeks, for 15 cycles. Patient received first dose of injection trastuzumab (450 mg) intravenously in the right (contralateral) arm and developed painful, swollen, erythematous blisters, and maculopapular rashes following the sharp linear borders of her previous radiation fields. She was reviewed by the medical oncologist and diagnosed as a rare case of RRD and treated with topical betamethasone cream. Causality assessment for RRD to trastuzumab was done using Naranjo and WHO-UMC scale and found to be in the category of probable and probable/ likely respectively.
\end{abstract}

Keywords: Breast cancer, Chemotherapy, Erythematous blisters, Maculopapular rashes, Radiation recall dermatitis (RRD), Radiotherapy, Trastuzumab

\section{INTRODUCTION}

Radiation recall dermatitis is an acute inflammatory reaction confined to previously irradiated areas that can be triggered when chemotherapy agents are administered after radiotherapy. ${ }^{1}$ Increased awareness may help in the early diagnosis and appropriate management as the phenomenon is poorly understood.

A diverse range of antineoplastic drugs for which radiation recall reactions have been most commonly reported include doxorubicin, docetaxel, paclitaxel, gemcitabine, also described with a variety of medications like antibiotics, anti-tubercular drugs, and simvastatin. ${ }^{2}$ Radiation recall is drug-specific for an individual patient, and is difficult to predict which patient will react to the particular drug, and rechallenge also does not induce the reaction uniformly. ${ }^{2}$

Trastuzumab is a recombinant humanized monoclonal antibody which acts by binding to the extracellular domain of HER-2/neu. This drug mainly blocks the binding of natural ligand, and also down regulates the receptor. Adjuvant trastuzumab therapy has been incorporated into the standard management of HER-2/neu positive tumours in patients with breast cancer, as there is improvement in 
disease control, and overall survival when used with other modalities of treatment (surgery, chemotherapy, and radiotherapy). Common adverse effects of trastuzumab are diarrhoea, insomnia, abdominal pain, injection site reactions, and cardiomyopathy. ${ }^{3}$

\section{CASE REPORT}

A 56 year old woman presented with a palpable mass in the left breast and was evaluated for the same, and diagnosed as invasive ductal carcinoma of stage $\mathrm{T}_{2} \mathrm{~N}_{3} \mathrm{cM}_{0}$. She had no significant previous medical/surgical history, and she received neoadjuvant chemotherapy with TCH regime consisting of inj. Trastuzumab 330mg, inj. Docetaxel 120mg and inj. Carboplatin 600mg for 4 cycles. She tolerated the treatment well.

Following completion of chemotherapy, she underwent left sided Modified Radical Mastectomy, and axillary lymph node dissection along with biopsy, she withstood the procedure well.

Following surgery, she received loco-regional adjuvant radiation therapy given in left chest wall and supraclavicular fossa area with fields/portals threedimensional conformal radiotherapy, X-rays, $6 \mathrm{MV}$ with dose fractions $4000 \mathrm{cGy} / 15 \mathrm{FR} / 5 \mathrm{FR} / \mathrm{WK}$. She tolerated treatment with minimal radiation induced dermatitis, erythema throughout the irradiated area and the skin healed gradually following the completion of radiotherapy.

Trastuzumab therapy as adjuvant chemotherapy was started 4 weeks after completion of radiotherapy for a total of 15 cycles, once a month. She received first cycle of inj. Trastuzumab $(450 \mathrm{mg})$ intravenously in the right (contralateral) arm on 21/10/2017, which was given on OPD basis.

Next day, she presented with painful, swollen and erythematous, maculopapular rashes and discolouration of skin in the area of previous radiation exposure. The erythematous region of the skin was very well demarcated, resembling the area of irradiated skin with sharp linear borders following the borders of her previous radiation fields, with non-irradiated fields unaffected. She was reviewed by the medical oncologist and diagnosed as a rare case of radiation recall dermatitis. Causality assessment was done and based on the information; this case had a NARANJO ADR probability score of 07. i.e., probable adverse drug reaction and according to WHO-UMC scalethe reaction was labelled as probable/likely. ${ }^{4,5}$ She was treated with topical betamethasone cream, and the brisk erythema reduced in two days but the oedema and dull aching pain in the left chest wall persisted for about two weeks.

Despite the recall reaction, she continued with the planned doses of inj. Trastuzumab, every 4 weeks for the next 14 cycles. She also received premedication with steroids and antihistamines. Intermittent exacerbations of discomfort in same areas of radiation exposure were observed during her subsequent trastuzumab treatment but the reaction was not as severe as radiation recall reaction. She completed the remaining cycles without any further episodes of radiation recall dermatitis.

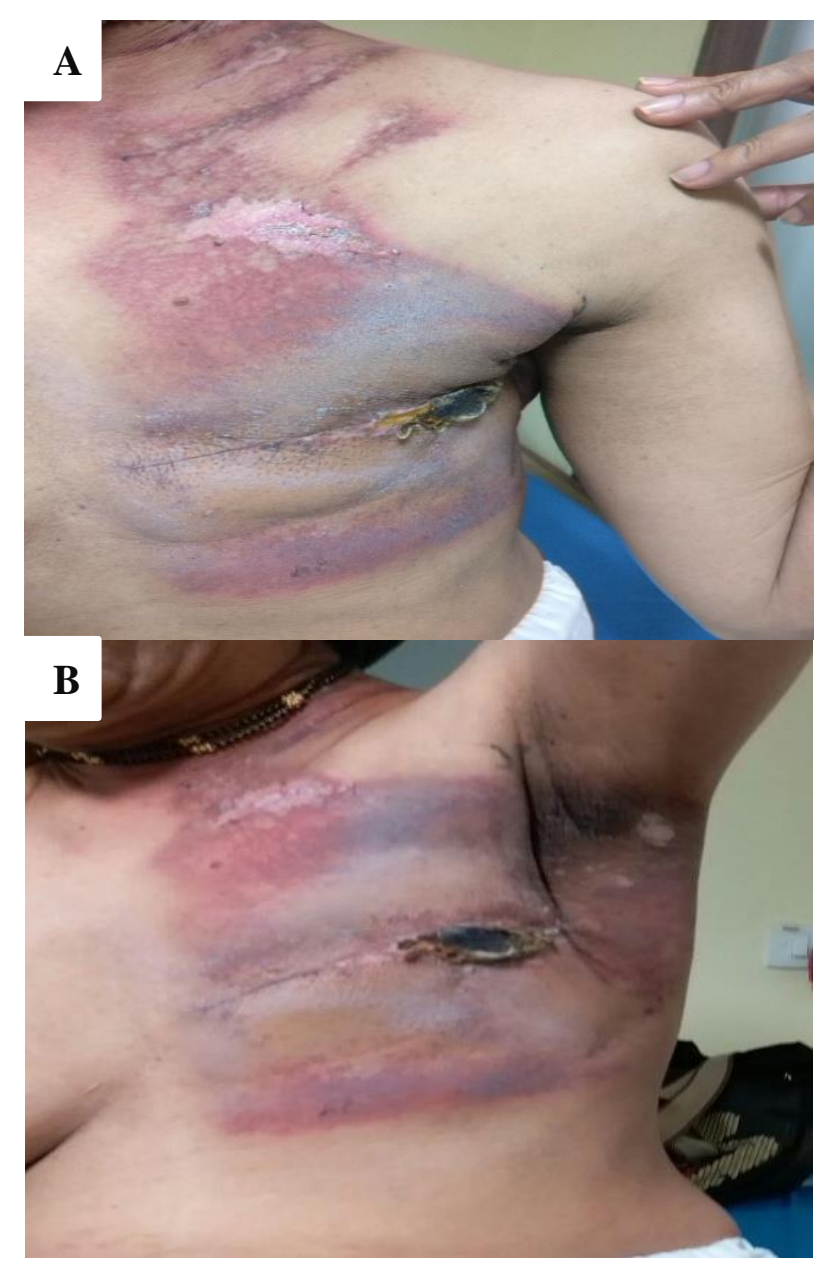

Figure 1 (A and B): Trastuzumab induced erythematous reaction in the areas of previous radiation exposure fields, (A) very well demarcated, sharp linear borders following previous radiation exposure, $(B)$ reaction with axillary involvement.

\section{DISCUSSION}

The reaction was first described by D' Angio with actinomycin $\mathrm{D}$ in a publication. ${ }^{6,7}$ According to data obtained from case reports, estimated frequency of RRD is found to be $8.8 \% .^{7}$

Even though, the exact pathophysiology is unknown, it may be attributable to epithelial stem cell deficiency, epithelial stem cell sensitivity, microvasculature damage, drug hypersensitivity or altered cutaneous immunologic responses. In vitro studies shown the radiation induced stable long term changes in the cell phenotype. The p53mediated signal transduction pathway activates the cellular response to DNA damage produced by ionizing radiation. ${ }^{7}$ 
A study conducted by Belkacemi et al, reported the concurrent use of trastuzumab with radiotherapy results in $51 \%$ grade $\geq 2$ acute radiation dermatitis in a French multicentric study, the incidence of RRD was higher than seen with adjuvant radiotherapy alone. ${ }^{8}$

The reaction may appear weeks to years after radiotherapy, and the severity of the reaction is extremely variable, it may range from maculopapular eruptions with erythema, vesicles, and desquamation to severe skin necrosis. For objective categorization of RRD, the National Cancer Institute Common Terminology Criteria for Adverse Events (CTCAE) version 3 acute skin scoring system is utilized. $^{2}$

According to review done by Camidge $\mathrm{R}$ and Price $\mathrm{A}$, the median interval between radiotherapy and chemotherapy in RRD, was considered approximately as 39.5 days (range 7-840 days). ${ }^{9}$ Most RRDs have occurred when radiotherapy, and chemotherapy are separated by less than 2 months. ${ }^{10}$

One should suspect an RRD, if a patient present with a skin reaction similar in appearance to acute radiation induced dermatitis with clearly defined edges which follows previous radiation exposure area. Diagnosis is usually based on clinical history and appearance. Histology may show atypia with vascular dilatation in the dermis in association with necrotic keratinocytes.

Even though the effect of rechallenge with the offending drug is unpredictable, the suspected drug can be continued with dose reduction or extended steroid cover. ${ }^{11}$

\section{CONCLUSION}

Even though RRD remains a poorly understood phenomenon, increased awareness may aid early diagnosis, and appropriate management. The risk can be minimized by prolonging the interval between completion of radiotherapy, and initiation of chemotherapy.

\section{ACKNOWLEDGEMENTS}

It is with immense gratitude; the author would like to thank the patient for her co-operation and patience.

Funding: No funding sources Conflict of interest: None declared

Ethical approval: Not required

\section{REFERENCES}

1. Moon D, Koo J, Suh C, Yoon C, Bae J, Lee S. Radiation recall dermatitis, induced by trastuzumab. Breast cancer. 2016;23(1):159-63.

2. Burris HA, Hurtig J. Radiation recall with anticancer agents. The oncologist. 2010;15:1227-37.

3. Lake DF. Immunopharmacology. Katzung BG. Basic and Clinical Pharmacology. $13^{\text {th }}$ ed. Indian edition: McGraw-Hill; 2015:961.

4. Naranjo CA, Busto U, Sellers EM, Sandor P, Ruiz I, Roberts EA, et al. A method for estimating the probability of adverse drug reactions. Clinical pharmacology and therapeutics. 1981;30(2):239-45.

5. World Health Organization. The use of the WHOUMC system for standardized case causality assessment. Uppsala: The Uppsala Monitoring Centre; 2005. Available at: http://www.who.int/medicines/areas/quality_safety/sa fety_efficacy/WHOcausality_assessment.pdf. Cited on $15 / 10 / 2018$.

6. D'Angio GJ, Farber S, Maddock CL. Potentiation of X-ray effects of actinomycin D. Radiology. 1959;73:175e177. Available at: https://pubs.rsna.org/doi/abs/10.1148/73.2.175?journ alCode=radiology. Cited on 15/10/2018.

7. Alsabbak H, Aljuboori Z, Spierer M and Klein P. The association of adjuvant trastuzumab (Herceptin) with radiation recall dermatitis. $J$ Can Sci Thera. 2013;05(12):427-9.

8. Belkacemi Y, Gligorov J, Ozsahin M, Marsiglia H, Lafontan BD, Laharie-Mineur $\mathrm{H}$, et al. Concurrent trastuzumab with adjuvant radiotherapy in HER2positive breast cancer patients: acute toxicity analyses from the French multicentric study. Annals of Oncol. 2008;19:1110-6.

9. Camidge R, Price A. Characterizing the phenomenon of radiation recall dermatitis. Radiotherapy and Oncol. 2001;59(3):237-45.

10. Hird AE, Wilson J, Symons S, Sinclair E, Davis M, Chow E. Radiation recall dermatitis: case report and review of the literature. Current Oncol. 2008;15(1):5362.

11. Shrimali RK, McPhail NJ, Correa PD, Fraser J, Rizwanullah M. Trastuzumab-induced radiation recall dermatitis-first reported case. Clinical Oncol. 2009;21(8):634-5.

Cite this article as: Anupama C, Anuradha HV, Maka VV. Trastuzumab induced radiation recall dermatitis: an interesting case. Int J Basic Clin Pharmacol 2018;7:2465-7. 